of when to stop a project. Mr. Paine pointed out that this is a matter of the persistent sharpening of technical judgment and instinct by hard experience. Arbitrary intervention by management without the fullest attempt to understand and utilize the judg. ment of the research personnel involved almost invariably results in stopping the wrong project.

Other subjects of general interest raised in the discussions at the conference included the transfer and flexibility of staff, the origin of research problems and ideas, in which distinction was drawn between the two aspects, discovery and invention, and the costing and the evaluation of research. Some of the difficulties in, and objections to, costing research were discussed, and the importance was emphasized of making costing as simple as possible, accepting it as an approximate activity and putting it over intelligently to the research staff. There was general agreement that evaluation of research work is desirable; but the difficulties of expressing its value in financial terms are practically insuperable.

\section{CONFERENCE ON DIELECTRICS}

A

CONFERENCE on dielectrics was held in Liverpool during July 23-25. The Conference was organized by the Department of Theoretical Physics of the University of Liverpool, in collabora. tion with the Department of Extra-Mural Studies of the University, the Institute of Physics and the Electrical Research Association.

Dielectrics is a subject which brings together people with very different backgrounds, including experimental and theoretical physicists, chemists and electrical engineers. Each group of subjects was therefore introduced by a fairly long review, summarizing the principal aspects or the recent advances connected with the subject for the benefit of those who are not working in that particular field. The reviews were followed by original contributions. These unfortunately had to be rather short because of the large number of papers presented.

The meetings were held in one of the residential halls of the University situated outside the city in pleasant surroundings, and all the meals were also served in the same building. The sittings were fairly short with long intervals for coffee, lunch and tea, which all helped to give plenty of opportunity for private discussions, which was one of the principal aims of the conference.

About a hundred and sixty people attended the meetings, a third of whom came from overseas. The distinguished visitors from abroad included E. Bauer (Paris), C. J. F. Böttcher (Leyden), R. H. Cole (Brown University), R. M. Fuoss (Yale University), M. Magat (Paris), J. C. Slater (Massachusetts Institute of Technology) and C. P. Smyth (Princeton).

The field which showed the greatest advance since the conference on the same subject held in Bristol in 1946 was that of the ferro-electrics. While the reasons for ferro-electricity were obscure in 1946, the main principles are now well understood.

A considerable amount of work was presented on the phase transitions of solid hydrogen halides, but the state of affairs is very complicated and a complete explanation of the connexion between the dielectric and structural changes of these materials at the transitions is still outstanding. Important results have been obtained on the electrical breakdown of liquids, and significant advances were also presented in many other fields.

The most controversial subject turned out to be the breakdown of solids.

The first day started with a short introduction to the Conference by H. Fröhlich. This was followed by a review by $J$. C. Slater of the theory of ferroelectricity and permanent polarization. Prof. Slater presented his subject in a remarkably clear way, so that even those who had known nothing about it previously grasped the principles of ferro-electricity. A. F. Devonshire explained that the electric and elastic constants of the non-cubic phases of barium titanate can be calculated from the constants of the cubic phase; but in order to use these results for the calculation of the constants of a ceramic, which is polycrystalline, one would have to average over crystallographic directions and it is not known how the averaging process is to be carried out. D. M. Finlayson reported measurements on potassium dihydrogen phosphate which showed that both the 'free' and the 'clamped' dielectric constants become independent of temperature at about $60^{\circ} \mathrm{K}$., whereas current theories suggest that this should occur at about $100^{\circ} \mathrm{K}$. The discrepancy indicates that down to $60^{\circ} \mathrm{K}$. small fields can induce a movement of the domain walls.

K. Huang presented two phenomenological equations and suggested that these make the treatment of the interaction of an ionic crystal with an electric field easier than previous methods. He showed how these equations can be applied to various problems, in particular to the transverse optical vibrations in the crystal. Two papers, by A. Schallamach and by C. G. Garton, discussed the distribution of relaxation times in amorphous materials. L. Hartshorn reviewed methods used for the measurement of dielectric constants with high accuracy and discussed the practical limitations. He explained why the accuracy is highest in the centimetre region. This review was followed by many very short communica. tions concerning experimental methods.

The second day' started with C. P. Smyth's excellent review on the connexion between chemical structure and dielectric properties. Prof. Smyth also mentioned some recent results concerning long-chain alcohols in long-chain organic solvents. For alcohols of moderate chain-length the relaxation time is independent of the viscosity of the solvent, which shows that the forces governing molecular rotation are not connected with the flow viscosity. But for alcohols with very long chains, the relaxation time is not independent of the flow viscosity of the solvent. J. Lamb presented measurements on solid pentamethyl-chlor-benzene and similar materials, which exhibit excellent Debye curves with scarcely any spread of relaxation times. These materials are so like the ideal theoretical model in behaviour because their molecules are very rigid and have very nearly circular cross-sections. R. H. Cole showed absorption curves of glycerine derivatives. He showed, with the aid of Cole-Cole plots, that a number of these compounds possess two distinct relaxation mechanisms. $\mathrm{He}$ also mentioned measurements on solid hydrogen bromide and said that by annealing it between the electrodes one gets rid of hysteresis effects and at the lowest transition the dielectric constant then reaches values of about 200 . D. H. Whiffen said that a number of non-polar liquids exhibit a very small dielectric absorption in the 
ultra-high-frequency range. T'here is no theoretical reason why such a small absorption should not take place and Dr. Whiffen offered one possible explanation. M. Magat discussed the absorption of various organic materials in the centimetre range. Aliphatic alcohols exhibit two distinct dispersion regions, both of which are due to relaxation mechanisms because both are strongly temperature-dependent. F. J. Lehany sum marized the results obtained in the National Stand. ards Laboratory, Sydney, on crystalline secondary alcohols. B. Szigeti discussed the theory of molecular torsion in long-chain ketones and showed that this mechanism leads to a polarizability which is very large compared with the values of 'vibrational' or 'atomic' polarizability encountered in most other substances. W. G. Oakes said that both crystalline rubber and polythene exhibit two distinct relaxation mechanisms. If the crystallinity of rubber is reduced, one of the absorption maxima disappears. E. Rushton discussed the dielectric properties of liquid silicones.

The third day started with two talks on solid hydrogen chloride and hydrogen bromide, by $\mathbf{E}$. Bauer and J. G. Powles. In the lowest-temperature phase, hydrogen bromide shows two dispersion regions due to relaxation mechanisms, and one of these disappears at the first transition. Prof. Bauer thinks that in the lowest-temperature phase hydrogen bromide should be considered as 'anti-ferro-electric'. In the same phase there is a large difference between the dielectric behaviour of hydrogen bromide and deuterium bromide, and Dr. Powles explained this by assuming that at very low temperatures polariza. tion can take place in the former by means of a tunnel effect.

R. Freymann demonstrated that dielectric measurements can distinguish between adsorbed and chemically-bound water in solids. V. Daniel discussed experiments which showed that very small amounts of impurities, in particular water, can have a very large effect on the dielectric properties near the melting point. C. Dodd and G. N. Roberts said that the dielectric properties of $a$ supercooled liquid exhibit a change at the melting point. J. J. O'Dwyer derived a phenomenological relation between the polarization and the electric field for very strong fields when the relationship is not linear. H. Pelzer spoke on the energy loss and effective mass of slow electrons in ionic crystals.

The discussion on dielectric breakdown was opened by $\mathrm{S}$. Whitehead, who reviewed the influence of theoretical developments on engineering practice. He stated that from the practical point of view little interest can be attached to the further improvements of the best dielectrics ; much more advantage can be gained from the improvement of those dielectrics which are not very good at present. K. A. Macfadyen reported measurements on the breakdown of liquids and concluded that liquids do not conform to the existing breakdown theories which have been developed for crystals or amorphous substances. Talking on breakdown in solids, W. Franz doveloped the view that several existing theories can account for the known experimental facts. H. B. Callen, on the other hand, maintained that preference can be given to one particular theory which alone is able to explain the fact that the breakdown path favours certain crystallographic directions. The conclusions of both Prof. Franz and Dr. Callen were contradicted by Prof. Fröhlich, and Dr. Callen's arguments were also criticized by Dr. Huang. With this discussion the conference came to an end.
Prior to the Conference there was a three-day 'summer school' on the theory of dielectrics. The lecturers were Prof. H. Fröhlich and Dr. B. Szigeti, and one lecture was also given by Dr. J. G. Powles. The school was arranged for the benefit of experimental physicists with theoretical interests.

B. SZIGETI

\section{BOSE INSTITUTE, CALCUTTA} ANNIVERSARY MEETING

7 HE thirty-fourth anniversary of the Bose Institute was celebrated on November 30, when Prof. P. C. Mahalanobis, statistical adviser to the Cabinet, Government of India, gave the thirteenth Acharya Jagadish Chandra Bose Memorial Lecture. His subject was "Statistical Methods in Relation to National Development". His Excellency Dr. H. C. Mookherjee, Governor of West Bengal, presided over the meeting.

In presenting his annual report, Dr. D. M. Bose, director of the Institute, referred to its severe loss through the death of Lady Abala Bose, , widow of Acharya Bose, and of Prof. N. C. Nag, who served as assistant director and was a trusted colleague of the founder. Speaking of Lady Bose, Dr. D. M. Bose said that those on whom the direction of the Bose Institute devolved after the death of the founder will recall with gratitude the help they constantly received from Lady Bose, by her advice, and by her presence at Council and governing body meetings. He then gave a short sketch of the life of Lady Bose and of the fifty years of her eventful married life, which terminated with the death of Acharya Bose in 1937. "It would be rare in any country," he said, "to find such instances of two gifted and strong personalities with similar ideals and in many ways with complementary characters, united in matrimony and fully utilizing their inborn gifts to the service of their country and of their fellow beings. One of them was temperamental, artistic, with a romantic imagination, dreaming of the resuscitation of the achievements of ancient India as exemplified in Taxila, Nalanda and Ajanta, interested more in putting concrete shape to his ideas rather than in individuals; the other calm and unruffled, with intuitive wisdom and human sympathy, which deepened with age and experience. After the death of her husband a now chapter of her life commenced." He also described her work on behalf of widows and other distressed women of Bengal through the institutions founded and managed by her for a period of thirty years.

Dr. Bose then gave an account of the principal sources of income of the Institute, the total income of which during the present year is expected to exceed Rs. 300,000. The Institute has received during the past three years a total non-recurring grant of about Rs. 300,000, of which Rs. 180,000 was contributed by the Govermment of India and Rs. 120,000 by the Sir J. C. Bose Trust No. 1. This amount has been spent principally in the erection and equipment of a new laboratory built on the top of the Institute lecture hall, and in the purchase of equipment for the workshop and laboratories.

The Government of West Bengal has agreed to acquire for the Falta' Agricultural Experiment Station of the Bose Institute about 58 bighas of Khas Mahal land at an estimated cost of about Rs. 48,000 , of which the Government will contribute 